\title{
Long-term changes in rainfall and tropical cyclone activity over South and Southeast Asia
}

\author{
H. G. Takahashi ${ }^{1,2}$ \\ ${ }^{1}$ Japan Agency for Marine-Earth Science and Technology (JAMSTEC), Kanagawa, Japan \\ ${ }^{2}$ Graduate School of Urban Environmental Sciences, Tokyo Metropolitan University (TMU), Tokyo, Japan
}

Received: 8 November 2010 - Revised: 26 April 2011 - Accepted: 26 April 2011 - Published: 9 May 2011

\begin{abstract}
Long-term changes in rainfall and associated tropical cyclone (TC) activity in transition seasons between the wet and dry seasons in South and Southeast Asia, namely boreal spring and fall, were examined, using gridded rainfall, TC tracks, and reanalysis datasets, the focus of discussion being the long-term changes in coastal regions. It was found that long-term changes in rainfall during the transition seasons in South and Southeast Asia were closely associated with those in TC activity over the north Indian Ocean and South China Sea. Rainfall in May increased in the last 40 years over and around Myanmar, which indicates an earlier monsoon onset over the western Indochina Peninsula. Rainfall over and around northern Vietnam also increased in the last 40 years during October, which is known as the monsoon retreat period. These increases were associated with the long-term changes in TC activity. Furthermore, although linear trends have been previously suggested, monotonically increasing or decreasing trends in these long-term changes were not found over the last 60 years.
\end{abstract}

\section{Introduction}

Long-term changes in rainfall are a major issue of climate change and could influence global circulation, through tropical latent heating, as well as agriculture and human health. Many studies have discussed long-term changes in rainfall in the last 100 years over tropical monsoon Asia. The Intergovernmental Panel on Climate Change (IPCC, 2007) reported the regional distribution of observed rainfall changes in summer, winter, and annually. That study, focused on the South Asian and East Asian monsoon regions, found that annual

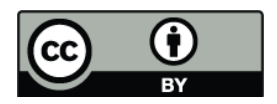

Correspondence to: H. G. Takahashi (hiroshi3@jamstec.go.jp) rainfall decreased over the last 60 years in India, while no clear signal was found over China. The long-term trends in rainfall varied seasonally and regionally.

Rainfall over South and Southeast Asia is strongly affected by tropical cyclone (TC) activity over the north Indian Ocean and western north Pacific/South China Sea. For example, Singh et al. (2000) showed that the frequency of TCs over the north Indian Ocean has increased in May and November and weakened in September over the last 100 years, which was likely to affect long-term changes in rainfall. Takahashi and Yasunari (2008) and Takahashi et al. (2009) analyzed observational data and proposed that the long-term decrease in September rainfall over Indochina in the second half of the twentieth century, which was found by Kanae et al. (2001), could be explained by the weakening of TC activity over the South China Sea and Philippine Sea regions in September. In addition, Takahashi et al. (2009) found that the long-term decrease in rainfall over the Indochina Peninsula was most significant along the eastern coast of Vietnam, where rainfall is strongly affected by TC activity. Takahashi and Yasunari (2008) also estimated the contribution of TCs including typhoons, tropical storms, tropical depressions, westward-moving intraseasonal disturbances, and residual lows to the total rainfall amount, finding that $70 \%$ of the rainfall was associated with TC activity.

Most studies have focused on the long-term changes in rainfall during a rainy season over South and Southeast Asia. However, seasonal transition periods have a significant impact on local people, influencing both agriculture and health. The timing of the beginning of the rainy season or monsoon onset is a particularly important issue. Thus, better understanding of the long-term changes in rainfall in the seasonal transition periods is also required. In addition, most previous studies have investigated the long-term changes in seasonal-mean precipitation, even though rainfall can vary within a season. In association with recent anthropogenic

Published by Copernicus Publications on behalf of the European Geosciences Union. 
global warming, long-term changes in TC activity over the whole globe have been discussed (e.g., Emanuel, 2005; Webster et al., 2005). However, although rainfall variations are associated with TC activity, the relationship between longterm changes in TC activity and those in rainfall over the Asian monsoon regions has not been discussed.

This study investigated recent long-term changes in rainfall the South and Southeast Asian monsoon regions and associated TC activity over the north Indian Ocean and South China Sea over the last 60 years. Because the rainfall in seasonal transition periods between wet and dry seasons is associated with TC activity over South and Southeast Asia, this study focused on these periods.

\section{Data and method}

Rainfall data were obtained from the Global Precipitation Climatology Centre (GPCC; Schneider et al., 2008) Version 4 dataset, which is a gridded precipitation product on a $0.5 \times 0.5$ global grid over land. This study used precipitation data from 1951 to 2007.

Changes in atmospheric circulation were investigated using the National Centers for Environmental Prediction/National Center for Atmospheric Research (NCEP/NCAR) reanalysis data (Kalnay et al., 1996). These data provided zonal and meridional winds $(u, v)$ at $850 \mathrm{hPa}$ on a $2.5 \times 2.5$ global grid. TC track data were provided by the Joint Typhoon Warning Center (JTWC).

The rainfall amount associated with TCs can partly be understood using TC track data. However, weaker TCs, including tropical depressions and residual lows, can also bring rainfall. Takahashi and Yasunari (2008) showed that weaker TCs also contribute to the total rainfall. To estimate TC activity including that of weaker TCs, the perturbation kinetic energy (PKE) of the low level winds was defined using high frequency components of $u$ and $v$, i.e.,

$\mathrm{PKE}=\frac{\overline{u^{\prime 2}+v^{\prime 2}}}{2}$

where the overbar denotes the time mean, and the prime is the high-frequency component. To reduce the effect of the seasonal and sub-seasonal components in the wind field, the high-frequency component was used. A 25-day running mean of zonal and meridional components was subtracted from the daily mean time series. An examination of the relationship between PKE and TC tracks suggested that PKE is sensitive to the frequency of TCs. The estimation of TC activity using low-level winds suggested that PKE may be similar to the accumulated cyclone energy (ACE; Bell et al., 2000) calculated at a grid point.

In this study PKE was also used to estimate the activity of TCs. Fortunately, this quantity is derived from an estimation of the eddy kinetic energy over mid-latitudes, which is appropriate for estimating the energy of mid-latitude cyclones. Thus, the PKE indicates the TC activity over the tropics, and the extra-tropical cyclone and frontal activity over mid-latitudes.

The 57-year study period was divided into three subperiods (1951-1969, 1970-1988, and 1989-2007, referred to as $\mathrm{P} 1, \mathrm{P} 2$, and $\mathrm{P} 3$, respectively) to facilitate the examination of long-term changes in rainfall and in TC activity. Coastal regions are the main area of focus, because the numbers of rain-gauge observation used for the gridded precipitation data over inland regions were much less compared with the coastal regions. Thus, one has to keep in mind that the gridded precipitation data over inland might not be regionally representative.

\section{Results}

This study focused on the transitional periods between dry and wet seasons, namely boreal spring and fall. March, April, and May are considered transitional period months from the dry season to the wet season because the summer monsoon starts in May or June and continues to September over South and Southeast Asia (e.g., Takahashi and Yasunari, 2006). Conversely, September, October, and November are transitional period months from the wet season to the dry season. To understand the long-term changes in the seasonal marches of rainfall and associated TC activity, all six months were investigated separately. The long-term changes in rainfall from P1 to P2 and from P2 to P3 are shown in Fig. 1. Figure 2 presents changes in TC activity estimated by PKE, while Fig. 3 shows the TC tracks for the three sub-periods. The differences in PKE are statistically significant at a $90 \%$ confidence limit, as determined using Student's t-test. Because interannual variations of TC activity are generally very large, the differences in PKE in some months were not significant.

\subsection{Transition period from dry to wet seasons}

A decrease in rainfall was observed from P1 to P2 over Indochina in March (Fig. 1). Although this decrease was somewhat consistent with the changes in TC activity (Fig. 2), the relationship was not clear. From P2 to P3, rainfall increased over the whole of Indochina in March. This increased rainfall was associated with TC activity or extra-tropical cyclone (frontal activity) over the South China Sea and Bay of Bengal, because rainfall in March, which is called the presummer monsoon rainfall, is associated with extra-tropical cyclones or frontal activity (Kiguchi and Matsumoto, 2005). Thus, pre-summer monsoon rainfall appears to be increasing in the last 40 years.

An increase in rainfall from $\mathrm{P} 1$ to $\mathrm{P} 2$ was found over northern Vietnam and southern China, while a decrease in rainfall over southern China from P2 to P3 was observed in April. 

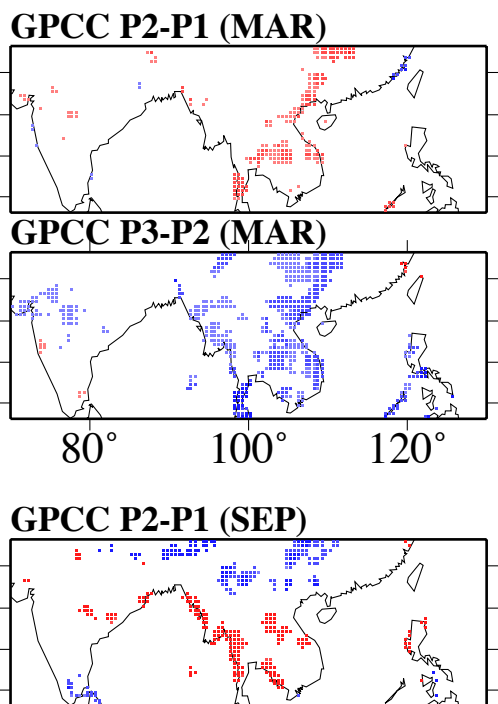

GPCC P3-P2 (SEP)

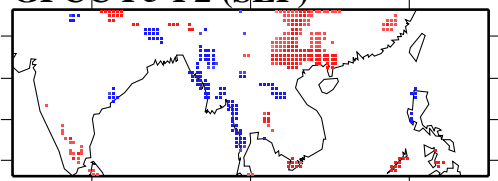

$80^{\circ} \quad 100^{\circ} \quad 120^{\circ}$
GPCC P2-P1 (APR)

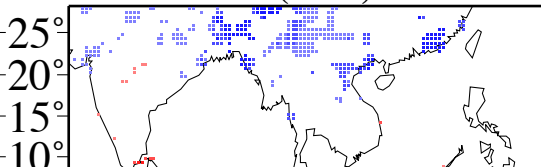

GPCC P3-P2 (APR)

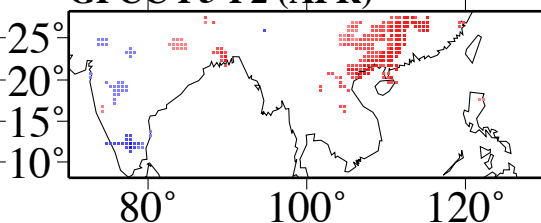

GPCC P2-P1 (OCT)

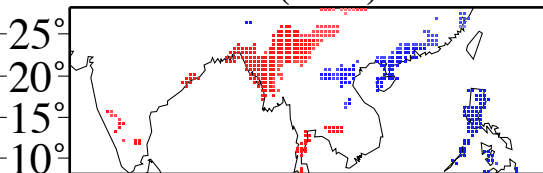

GPCC P3-P2 (OCT)
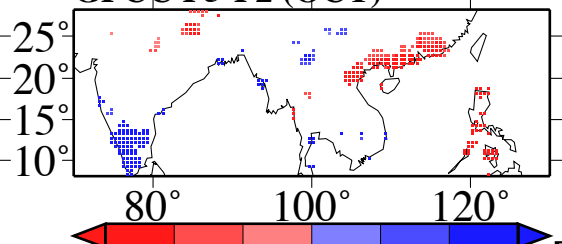

GPCC P2-P1 (MAY)

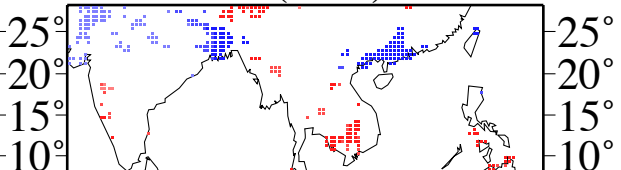

GPCC P3-P2 (MAY)

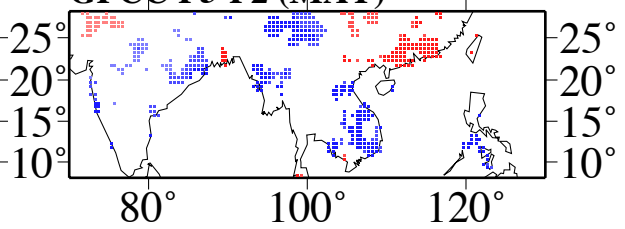

GPCC P2-P1 (NOV)

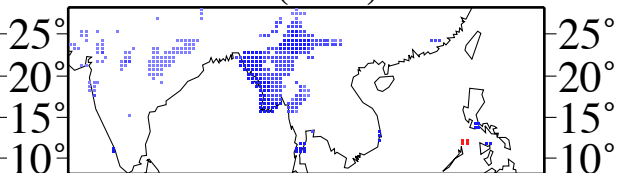

GPCC P3-P2 (NOV)

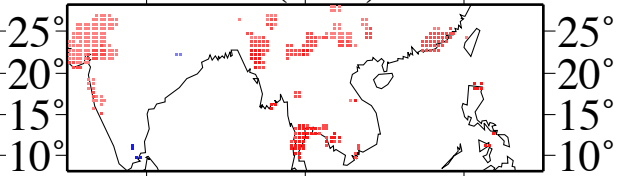

$-60-40-20 \quad 0 \quad 20 \quad 40 \quad 60[\mathrm{~mm} / \mathrm{month}]$

Fig. 1. Spatial distribution of long-term changes in monthly rainfall over South and Southeast Asia for March, April, May, September, October, and November from P1 to P2 and from P2 to P3. These differences plotted in this figure are statistically significant at a $90 \%$ confidence limit, as determined using Student's t-test. Unit is $\mathrm{mm} \mathrm{month}^{-1}$.

The long-term changes in rainfall could not be explained by those of the TC activity in April.

Over and around Myanmar, rainfall increased over the last 40 years from P2 to P3 in May (Fig. 1). The increase indicated that the monsoon rainfall during P3 started earlier than during P2. Over the northern Bay of Bengal, TC activity was enhanced from P2 to P3 (Fig. 2). Therefore, the recent increase in rainfall in May or earlier onset of the summer monsoon over and around Myanmar was associated with the enhancement of TC activity over the Bay of Bengal. However, the long-term weakening of TC activity over the head of Bay of Bengal from P1 to P2 was not associated with an increase in rainfall over Bangladesh. In addition, rainfall increased over southern China from P1 to P2, whereas a decrease in rainfall over southern China was observed from $\mathrm{P} 2$ to $\mathrm{P} 3$ in May. Along the eastern coast of Vietnam, an increase in rainfall was found from P2 to P3 in May. There, the increase in rainfall was explained by the increase in TC frequency from P2 to P3.

The long-term changes in TC and extra-tropical cyclone activity can partly explain the observed long-term changes in rainfall in northern spring over and around the Indochina Peninsula. However, over southern China, the observed longterm changes in rainfall could not be explained by the TC ac- tivity or extra-tropical cyclone activity in the northern spring. Thus, the changes may have been a local phenomenon. The cause of the long-term changes in southern China is a subject for further study.

\subsection{Transition period from wet to dry seasons}

A decrease in rainfall over the eastern coast of the Indochina Peninsula from P1 to P2 in September (Fig. 1) is consistent with the long-term change in rainfall uncovered by Takahashi et al. (2009), although that definition of the sub-period differs from the one used here. Another long-term decrease in rainfall from $\mathrm{P} 1$ to $\mathrm{P} 2$ was found along the coast around the head of the Bay of Bengal (from the Indian subcontinent to Myanmar) in September (Fig. 1). The decrease in rainfall from P1 to P2 in September was observed along the longitudinal band about $15^{\circ} \mathrm{N}$. Interestingly, that longitudinal band corresponded to a band of frequent TC activity of September from the South China Sea to the Bay of Bengal. Associated with the decrease, a drastic weakening of TC activity from P1 to P2 was observed over the South China Sea, the Bay of Bengal, and northern India (Figs. 2 and 3). Along the western coast of Indochina, a September rainfall increased from P2 to $\mathrm{P} 3$, while a decrease in rainfall was observed over northern Vietnam and southern China $\left(105-110^{\circ} \mathrm{E}, 20-30^{\circ} \mathrm{N}\right)$ from 
PKE(850hPa; NCEP1) P2-P1 (MAR)PKE(850hPa; NCEP1) P2-P1 (APR) PKE(850hPa; NCEP1) P2-P1 (MAY)

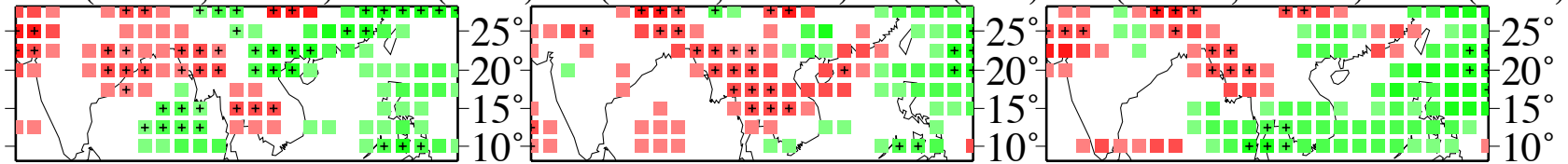

PKE(850hPa; NCEP1) P3-P2 (MAR)PKE(850hPa; NCEP1) P3-P2 (APR) PKE(850hPa; NCEP1) P3;P2 (MAY)
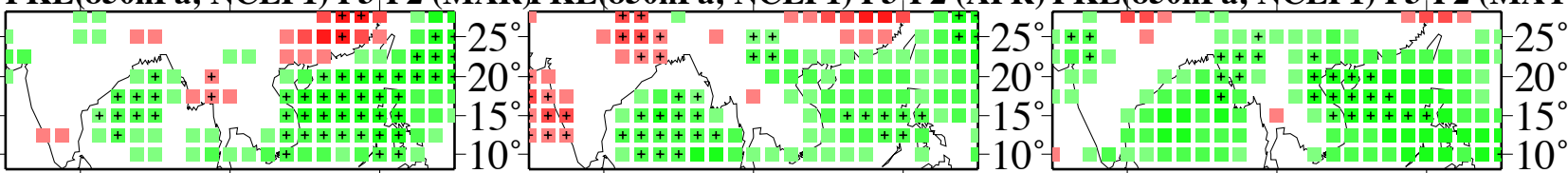
$80^{\circ}$
$100^{\circ}$
$120^{\circ}$

$80^{\circ}$

$100^{\circ}$

$120^{\circ}$

$80^{\circ}$

$100^{\circ}$

$120^{\circ}$

PKE(850hPa; NCEP1) P2-P1 (SEP)
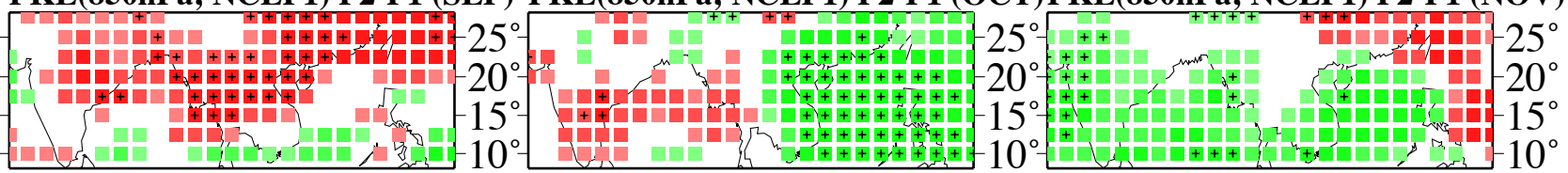

PKE(850hPa; NCEP1) P3-P2 (SEP) PKE(850hPa; NCEP1) P3-P2 (OCT) PKE(850hPa; NCEP1) P3-P2 (NOV)
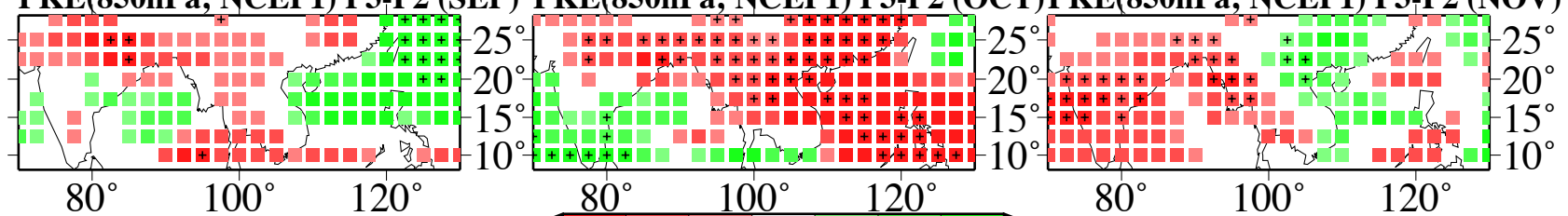

$80^{\circ} \quad 100^{\circ} \quad 120^{\circ}$

$\frac{80^{\circ} 100^{\circ} 120^{\circ}}{-4.0-2.0-1.0-0.50 .51 .02 .04 .0}$

Fig. 2. Spatial distribution of long-term changes in PKE over South and Southeast Asia for March, April, May, September, October, and November from P1 to P2 and from P2 to P3. Differences significant at the $90 \%$ level are indicated by black + marks, as determined using Student's t-test. Unit is $\mathrm{m}^{2} \mathrm{~s}^{-2}$.

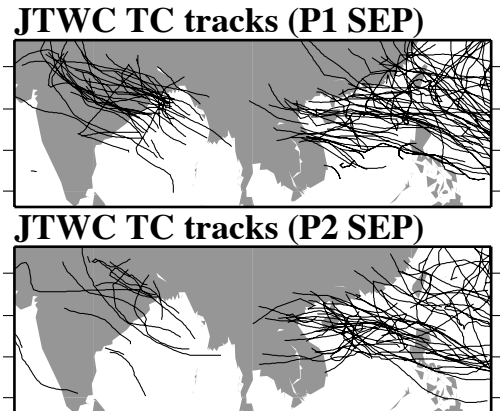

JTWC TC tracks (P3 SEP)

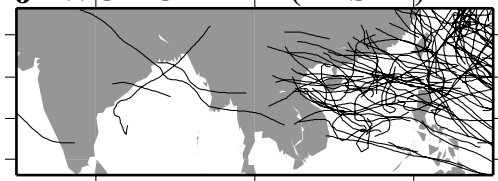

$80^{\circ}$

$100^{\circ}$

$120^{\circ}$

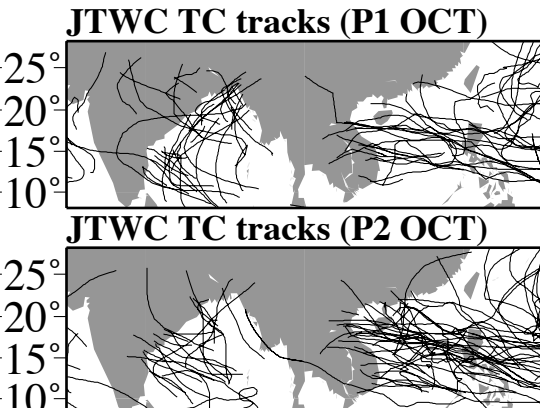

JTWC TC tracks (P3 OCT)

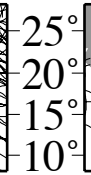

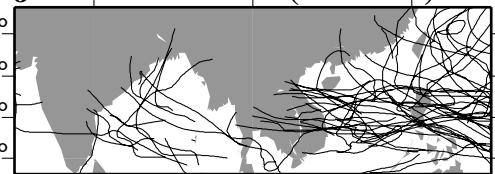

$80^{\circ}$

$100^{\circ}$

$120^{\circ}$

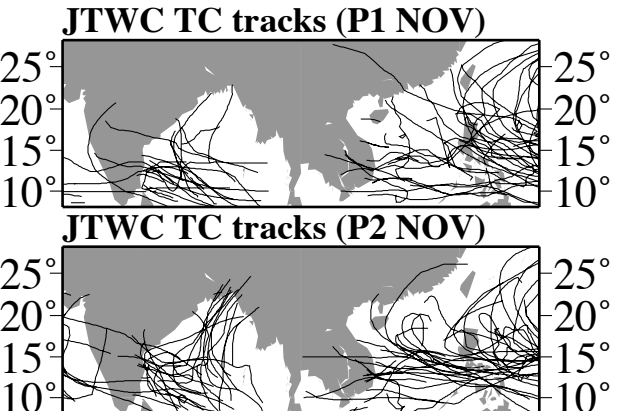

JTWC TC tracks (P3 NOV)

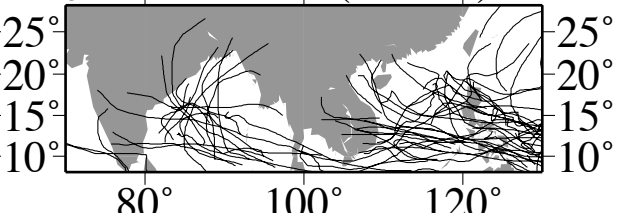

Fig. 3. Long-term changes in JTWC TC tracks for September, October, and November during the three sub-periods, P1, P2 and P3.

P2 to P3 (Fig. 1). Long-term change in TC activity over the Bay of Bengal may explain the observed long-term changes in September rainfall over and around Myanmar from P2 to $\mathrm{P} 3$. However, because the long-term changes in TC activity and TC tracks from P2 to P3 in September were not clear and not statistically significant, the long-term changes in TC activity cannot always explain the cause of long-term changes in rainfall from $\mathrm{P} 2$ to $\mathrm{P} 3$ in September. 
A long-term increase in rainfall over northern Vietnam and Philippines from P1 to P2 was observed in October (Fig. 1), which was associated with the enhancement of TC activity over and around the South China Sea (Fig. 2). In addition, TC tracks increased over the South China Sea from P1 to P2 (Fig. 3). Thus, from P1 to P2, TC activity and rainfall around northern Vietnam decreased in September and increased in October. On the other hand, rainfall in October decreased over Myanmar from P1 to P2, which was also associated with the decline of TC activity over the Bay of Bengal (Fig. 2). Over the Bay of Bengal, northeastward TC activity declined from P1 to P2 (Fig. 3). Moreover, rainfall decreased in northern Vietnam and southern China from P2 to P3 in October (Fig. 1), associated with the southward shift of the major courses of TCs over the South China Sea (Fig. 3).

An increase in November rainfall was observed over Myanmar from P1 to P2, associated with the enhanced TC activity estimated from PKE (Fig. 2) and the increase in northwestward TCs over the Bay of Bengal (Fig. 3). A decrease in rainfall in November was found over the western part of the Indochina Peninsula and southern China from P2 to P3. The decrease in November rainfall around the Bay of Bengal was consistent with the decrease in TC activity over the Bay of Bengal.

In this manner, most of the long-term changes in rainfall over South and Southeast Asia in northern fall were associated with TC activity. Although the datasets used were not of high quality in some parts of the study period, the three independent datasets were in close agreement regarding the long-term changes. Therefore, the observed longterm changes in these datasets can be tentatively considered real phenomena for now. However, continuous analysis and cross-check studies are necessary to confirm the changes. In general, long-term changes in rainfall cannot all be responsible for the changes in the eddy components of large-scale circulation, such as TC activity. Hence further investigation of the causes of these changes is needed.

\section{Discussion}

In this section, the quality of the long-term datasets is duscussed. In general, the datasets used in this study included some artificial trends and bias. Thus, the long-term changes were carefully studied, particularly in rainfall. Despite the fact that GPCC Version 4 datasets were used to investigate the long-term changes in rainfall over the South and Southeast Asian monsoon regions, a cross-check was also performed, using APHRODITE (Yatagai et al., 2009) Version 1003R1 datasets. The long-term changes in rainfall described in the previous section were also found in the APRHODITE datasets. However, it is difficult to confirm whether the long-term changes in rainfall over inland regions of monsoon Asia are due to an artificial error or due to the fact that few rain-gauge data were available over long time periods, except for coastal regions. In addition, although most previous studies (e.g., IPCC, 2007) discussed linear trends in rainfall and other meteorological variables, longterm changes in rainfall over the South and Southeast Asian monsoon regions are difficult to interpret as monotonically increasing or decreasing functions.

\section{Conclusions}

In this paper, long-term changes in rainfall during transitional periods were described along with the associated TC activity over the north Indian Ocean and the South China Sea over the last 60 years, using the GPCC gridded precipitation, JTWC TC tracks, and NCEP/NCER reanalysis data.

The results indicate that long-term changes in rainfall in the South and Southeast Asian monsoon regions are strongly controlled by the TC activity over the north Indian Ocean and South China Sea, particularly in northern fall. Over and around Myanmar, the rainfall in May increased over the last 40 years, which was responsible for the enhancement of TC activity over the Bay of Bengal. Therefore, the monsoon onset over western Indochina has become earlier. On the other hand, a weakening of TC activity and a decrease in rainfall over western Indochina were observed over the last 40 years in November, which is a major TC month over the north Indian Ocean. In the last 60 years over northern Vietnam, the rainfall in September (the peak in the annual cycle) has decreased, whereas the rainfall in October (the monsoon retreat season) has increased. Hence, the rainy season has become longer over northern Vietnam due to TC activity changes.

It is noteworthy that the long-term changes in rainfall varied seasonally and regionally. In addition, the long-term changes in rainfall and TC activity were nonlinear. Hence, further detailed analysis with a focus on the physical processes is required.

Acknowledgements. The author thanks two anonymous reviewers for their helpful suggestions and comments. This work was partly supported by the Global Environment Research Fund (A-0902) of the Ministry of the Environment, Japan.

Edited by: S. Michaelides and S. Athanasatos

Reviewed by: two anonymous referees 


\section{References}

Bell, G., Halpert, M., Schnell, R., Higgins, R., Lawrimore, J., Kousky, V., Tinker, R., Thiaw, W., Chelliah, M., and Artusa, A.: Climate assessment for 1999, B. Am. Meteorolog. Soc., 81, 150, 2000.

Emanuel, K.: Increasing destructiveness of tropical cyclones over the past 30 years, Nature, 436, 686-688, 2005.

IPCC: Climate Change 2007: The Physical Science Basis. Contribution of Working Group I to the Fourth Assessment Report of the Intergovernmental Panel on Climate Change, Cambridge University Press, Cambridge, United Kingdom and New York, NY, USA, 996 pp., 2007.

Kalnay, E., Kanamitsu, M., Kistler, R., Collins, W., Deaven, D., Gandin, L., Iredell, M., Saha, S., White, G., Woollen, J., Zhu, Y., Leetmaa, A., Reynolds, R., Chelliah, M., Ebisuzaki, W., Higgins, W., Janowiak, J., Mo, K. C., Ropelewski, C., Wang, J., Jenne, R., and Joseph, D.: The NCEP/NCAR 40-year reanalysis project, Bull. Am. Meteorol. Soc., 77, 437-472, 1996.

Kanae, S., Oki, T., and Musiake, K.: Impact of deforestation on regional precipitation over the Indochina Peninsula, J. Hydrometeorol., 2, 51-70, 2001.

Kiguchi, M. and Matsumoto, J.: The rainfall phenomena during the pre-monsoon period over the Indochina peninsula in the GAMEIOP year, J. Meteorol. Soc. Jpn, 83, 89-106, 2005.
Schneider, U., Fuchs, T., Meyer-Christoffer, A., and Rudolf, B.: Global precipitation analysis products of the GPCC, Deutscher Wetterdienst, 12 available at: http://gpcc.dwd.de., 2008.

Singh, O., Ali Khan, T., and Rahman, M.: Changes in the frequency of tropical cyclones over the North Indian Ocean, Meteorol. Atmos. Phys., 75, 11-20, 2000.

Takahashi, H. and Yasunari, T.: A climatological monsoon break in rainfall over Indochina-A singularity in the seasonal march of the Asian summer monsoon, J. Climate, 19, 1545-1556, 2006.

Takahashi, H. and Yasunari, T.: Decreasing trend in rainfall over Indochina during the late summer monsoon: Impact of tropical cyclones, J. Meteorol. Soc. Jpn., 86, 429-438, 2008.

Takahashi, H., Yoshikane, T., Hara, M., and Yasunari, T.: Highresolution regional climate simulations of the long-term decrease in September rainfall over Indochina, Atmos. Sci. Lett., 10, 14-18, 2009.

Webster, P., Holland, G., Curry, J., and Chang, H.: Changes in tropical cyclone number, duration, and intensity in a warming environment, Science, 309, 1844-1846, 2005.

Yatagai, A., Arakawa, O., Kamiguchi, K., Kawamoto, H., Nodzu, M., and Hamada, A.: A 44-year daily gridded precipitation dataset for Asia based on a dense network of rain gauges, SOLA, 5, 137-140, 2009. 